\title{
Effect of Copolymerization Time on the Microstructure and Properties of Polypropylene/Poly(ethylene-co-propylene) In-Reactor Alloys
}

\author{
By Yandi FAN, ${ }^{1}$ Chunyu ZHANG, ${ }^{2}$ Yanhu XUE, ${ }^{1}$ Wei NIE, ${ }^{1}$ Xuequan ZHANG, ${ }^{2}$ \\ Xiangling $J I^{1, *}$ and Shuqin $B O^{1, *}$
}

Three Polypropylene/Poly(ethylene-co-propylene) (PP/EPR) in-reactor alloys produced by a two-stage slurry/gas polymerization had different ethylene contents and mechanical properties, which were achieved by controlling the copolymerization time. The three alloys were fractionated into five fractions via temperature rising dissolution fractionation (TRDF), respectively. The chain structures of the whole samples and their fractions were analyzed using high-temperature gel permeation chromatography (GPC), Fourier transform infrared (FT-IR), ${ }^{13} \mathrm{C}$ nuclear magnetic resonance $\left({ }^{13} \mathrm{C}\right.$ NMR), and differential scanning calorimetry (DSC) techniques. These three in-reactor alloys mainly contained four portions: ethylenepropylene random copolymer (EPR), ethylene-propylene (EP) segmented and block copolymers, and propylene homopolymer. The increased copolymerization time caused the increased ethylene content of the sample. The weight percent of EPR, EP segmented and block copolymer also became higher. The more EPR content indeed improves the toughness of the alloy but lowers its stiffness. Increasing the ethylene content in the EPR fraction and EP segmented and block copolymer, as well as the suitable content of EPR, is believed to be the key factors resulting in the excellent toughnessstiffness balance of in-reactor alloys.

KEY WORDS: PP/EPR In-Reactor Alloy / Fractionation / Microstructure /

Isotactic polypropylene (iPP) is a thermoplastic material widely used as it offers interesting combinations of good mechanical performance, heat resistance, and fabrication flexibility. However, it has relatively poor impact resistance, especially at low temperatures. Its toughness could be improved by a variety of elastomers, ${ }^{1-3}$ by adding a nucleating agent that reduces the average dimensions of the spherulites. ${ }^{4}$ The toughness could also be improved by copolymerization of propylene with ethylene or other olefins, ${ }^{5-10}$ among which the copolymerization with ethylene is one of the most useful and effective methods. Polypropylene/poly(ethylene-co-propylene) $(\mathrm{PP} / \mathrm{EPR})$ in-reactor alloys have been industrialized on a large scale.

The in-reactor blending technology was developed by Montell Company, hence opening up new horizons for polyolefin materials. The technology involves bulk polymerization of propylene and gas-phase copolymerization of ethylene and propylene using spherical superactive $\mathrm{TiCl}_{4} / \mathrm{MgCl}_{2}$ based catalyst systems. ${ }^{11-14}$ The use of a spherical catalyst allows a wider range of rubber content in the alloy and better control over phase structure to be achieved. The resulting spherical granules can be directly processed, eliminating the need for pelleting.

The mechanism of the two-stage in-reactor blending technology is very complicated, depending on the nature of active species in the catalysts and polymerization process. Xu et al. had proposed that the iPP with active center still can copolymerized with propylene and ethylene in the second stage. ${ }^{6}$ A previous investigation of the composition and chain structure of the PP/EPR in-reactor alloy showed that it is a multiphase copolymer system, ${ }^{15,16}$ consisting of an ethylenepropylene random copolymer (EPR), a series of ethylenepropylene segmented copolymers with different sequence lengths of polyethylene (PE) and polypropylene (PP) segments, and a propylene homopolymer. In comparison to iPP and EP copolymer alloys formed by mechanical blending, alloys prepared by in-reactor blending techniques exhibit very good impact-resistant property due to the unique microstructure. ${ }^{13,17}$ Some researchers proposed that ethylene-propylene (EP) segmented copolymers with long sequences might behave as a compatibilizer that enhances the interfacial adhesion between the random copolymer and propylene homopolymer. ${ }^{13,15,17}$ In such studies, the synergistic effects between the random copolymer portion and the segmented copolymer portion were found to have played an important role in enhancing the impact property of the alloy at low temperatures. The content and composition of different components have a key influence on the properties of the PP/EPR alloys. If the alloy contains more than $10 \mathrm{wt} \%$ of EPR with very low modulus, this kind of toughened PP suffers from a significant drop in flexural

\footnotetext{
${ }^{1}$ State Key Laboratory of Polymer Physics and Chemistry, Changchun Institute of Applied Chemistry, Chinese Academy of Sciences, Changchun, 130022, People's Republic of China

${ }^{2}$ Laboratory of Polymer Engineering, Changchun Institute of Applied Chemistry, Chinese Academy of Sciences, Changchun, 130022, People's Republic of China

*To whom correspondence should be addressed (Tel: +86-431-8526-2876, Fax: +86-431-8568-5653, E-mail: xlji@ciac.jl.cn).
} 
modulus as compared to PP homopolymer. However, For applications of the alloy as a high-performance structural material, further improvement in the balance between toughness and stiffness is a must.

Temperature rising elution fractionation (TREF), a technique that fractionates semicrystalline polymers according to their solubility-temperature relationship, has been widely used to characterize the compositional heterogeneity of polyolefins. ${ }^{18,19}$ Recently, thermal fractionation methods, such as stepwise isothermal crystallization (SIC) and successive selfnucleation and annealing (SSA) by differential scanning calorimetry (DSC), have been developed to analyze the structural heterogeneity of molecular chains. ${ }^{20-22}$ SSA is based on the sequential application of self-nucleation and annealing steps to a polymer sample. After thermal conditioning, a final DSC heating run reveals the distribution of melting points. These melting points were induced by SSA treatment as a result of the heterogeneous nature of the chain structure of the polymer. SSA is performed at a substantially shorter time than SIC, SSA also has better resolution. ${ }^{23}$ Therefore, applying SSA to obtain detailed information on the structure of alloy fractions should be possible.

In this paper, three PP/EPR in-reactor alloys produced by a two-stage slurry/gas polymerization procedure, with different ethylene contents and mechanical properties by controlling the copolymerization time, were fractionated into five fractions, respectively. The microstructure of these three alloys and their fractions were studied by GPC, FT-IR, ${ }^{13} \mathrm{C}$ NMR and DSC. The investigation the influence of copolymerization time on both the microstructure and properties will be helpful to elucidate the relationship between the microstructure and properties, and further produce the alloys with a good balance between toughness and stiffness.

\section{EXPERIMENTAL}

\section{Materials}

The four samples used in this study were synthesized in our institute and were coded as samples A, B, C, and D, respectively. A two-stage polymerization procedure was adopted using high-activity $\mathrm{TiCl}_{4} / \mathrm{MgCl}_{2}$ catalyst. The isotactic polypropylene (iPP) homopolymer particles (sample A) were first produced in bulk slurry at $80^{\circ} \mathrm{C}$ for $1 \mathrm{~h}$ under high pressure. The second stage ethylene-propylene copolymerization was performed in gas phase for 30, 60, and $90 \mathrm{~min}$ corresponding to samples $\mathrm{B}, \mathrm{C}$, and $\mathrm{D}$, respectively. The ethylene contents of $\mathrm{B}, \mathrm{C}$, and $\mathrm{D}$ were $3.4,12.1$, and $30.3 \mathrm{~mol} \%$ from the NMR results, respectively. The mechanical properties of the samples are listed in Table I. The impact strengths (Notched Izod) of alloys B, C, and D at $23^{\circ} \mathrm{C}$ were $10.9,39.1$, and $55.8 \mathrm{~kJ} / \mathrm{m}^{2}$, which were higher than that of sample A $\left(4.4 \mathrm{~kJ} / \mathrm{m}^{2}\right)$. Meanwhile, the flexural moduli of the alloys were $1.33,1.11$, and $1.05 \mathrm{GPa}$ for $\mathrm{B}, \mathrm{C}$, and $\mathrm{D}$, respectively; these figures were lower than that of $A$ $(1.40 \mathrm{GPa})$. It should be mentioned that sample D had a $9.4 \mathrm{~kJ} / \mathrm{m}^{2}$ impact strength at $-20^{\circ} \mathrm{C}$. Sample D had an
Table I. The chemical composition and mechanical properties of samples

\begin{tabular}{ccccccc}
\hline Sample & $\begin{array}{c}\mathrm{C}_{2} \\
(\mathrm{~mol} \%)\end{array}$ & $\begin{array}{c}\mathrm{MFI} \\
(\mathrm{g} / 10 \mathrm{~min})\end{array}$ & $\begin{array}{c}\text { Flexural } \\
\text { Strength } \\
(\mathrm{MPa})\end{array}$ & $\begin{array}{c}\text { Flexural } \\
\text { Modulus } \\
(\mathrm{GPa})\end{array}$ & \multicolumn{2}{c}{$\begin{array}{c}\text { Notched Izod } \\
\text { Impact Strength }\left(\mathrm{kJ} / \mathrm{m}^{2}\right)\end{array}$} \\
\hline $\mathrm{A}$ & 0 & 0.45 & 50.3 & 1.40 & 4.4 & - \\
$\mathrm{B}$ & 3.4 & 0.95 & 46.9 & 1.33 & 10.9 & - \\
$\mathrm{C}$ & 12.1 & 1.69 & 38.0 & 1.11 & 39.1 & - \\
$\mathrm{D}$ & 30.3 & 1.08 & 32.1 & 1.05 & 55.8 & 9.4 \\
\hline
\end{tabular}

excellent balance of stiffness and toughness based on the property data.

\section{Temperature Rising Dissolution Fractionation}

About $10 \mathrm{~g}$ of polymer was placed into $2 \mathrm{~L}$ of flask; $1 \mathrm{~L}$ of xylene was added to obtain $1 \%$ solution (w/v) at $135^{\circ} \mathrm{C}$. $1 \times 10^{-3} \mathrm{~g} / \mathrm{mL} \mathrm{2,}$ 6-di-tert-butyl-4-methylphenol (BHT) was added to xylene as antioxidant. The mixture was heated for about $3 \mathrm{~h}$ at $135^{\circ} \mathrm{C}$. The solution was then cooled to room temperature at a rate of $2{ }^{\circ} \mathrm{C} / \mathrm{h}$ and was kept at room temperature for $24 \mathrm{~h}$; finally, it was separated into two phases: the concentrated phase and the dilute phase. The concentrated phase was filtered and washed with xylene. Fraction 1 was obtained after concentrating the dilute phase, hence precipitating the polymer, washing with acetone, and drying the fractions in vacuum. The concentrated phase was placed into a cylindrical container made of nickel net; it was then put into a similar cylindrical glass bottle, and about $250 \mathrm{~mL}$ of xylene was added. The bottle was maintained at $80^{\circ} \mathrm{C}$ for $24 \mathrm{~h}$. After $12 \mathrm{~h}$, the solution in the bottle was removed and was replaced with hot xylene. Finally, the net with insoluble polymer was taken out and washed with hot xylene $\left(80^{\circ} \mathrm{C}\right)$. The solutions collected twice in this step were mixed together, cooled, precipitated with twice the volume of acetone, and filtered. The obtained polymer, named fraction 2 , was then dried in vacuum. Fractions 3 and 4 , soluble at $100^{\circ} \mathrm{C}$ and $115^{\circ} \mathrm{C}$, respectively, were obtained following the same procedure for fraction 2 . The polymer insoluble at $115^{\circ} \mathrm{C}$, named fraction 5 , was washed by acetone and dried in vacuum.

\section{Characterization of Samples and Fractions}

The molecular weight and molecular weight distribution (MWD) of the samples and their fractions, were determined by a PL-GPC 220 high-temperature gel permeation chromatography (Polymer Laboratories Ltd) at $150{ }^{\circ} \mathrm{C}$. The columns used were three PLgel $10 \mu \mathrm{m}$ mixed-B LS columns $(300 \mathrm{~mm} \times$ $7.5 \mathrm{~mm}$ ). The eluent was 1,2,4-trichlorobenzene with $5 \times 10^{-4}$ $\mathrm{g} / \mathrm{mL}$ BHT as antioxidant, it was filtered with a $0.2 \mu \mathrm{m}$ poresize membrane before use. The injection volume was $200 \mu \mathrm{L}$, and the flow rate was $1.0 \mathrm{~mL} / \mathrm{min}$. Calibration was made by polystyrene standard EasiCal PS-1 (PL Ltd.).

Fourier transform infrared spectra were recorded on a Bruker Vertex 70 spectrometer. The thin films of the polymer prepared by hot pressing were used as samples.

${ }^{13} \mathrm{C}$ NMR spectra were measured at $130{ }^{\circ} \mathrm{C}$ on a Varian Unity $400 \mathrm{MHz}$ NMR spectrometer. Polymer solutions were 
prepared with $70-75 \mathrm{mg}$ of polymer in $0.5 \mathrm{~mL}$ of deuterated $o$-dichlorobenzene at $130^{\circ} \mathrm{C}$.

Differential scanning calorimetry (DSC) scans were recorded on a TA Instrument model DSC Q100. About $5 \mathrm{mg}$ of the sample was sealed in an aluminum sample pan, it was initially heated from 20 to $200^{\circ} \mathrm{C}$ at a rate of $10{ }^{\circ} \mathrm{C} / \mathrm{min}$, held at $200^{\circ} \mathrm{C}$ for $5 \mathrm{~min}$ to remove its thermal history, then cooled from 200 to $20^{\circ} \mathrm{C}$ at $10^{\circ} \mathrm{C} / \mathrm{min}$, held at $20^{\circ} \mathrm{C}$ for $1 \mathrm{~min}$, and finally heated again to $200^{\circ} \mathrm{C}$ at $10^{\circ} \mathrm{C} / \mathrm{min}$. Temperature calibration was performed using indium. The successive self-nucleation and annealing (SSA) method used was presented in the original paper of Müller et al. ${ }^{20}$ The annealing time was kept at $5 \mathrm{~min}$; heating and cooling were done at a rate of $10{ }^{\circ} \mathrm{C} / \mathrm{min}$. In all the measurements, the first $T_{\mathrm{s}}$ temperature was chosen from predetermined values $\left(167^{\circ} \mathrm{C}, 164^{\circ} \mathrm{C}, 160^{\circ} \mathrm{C}\right.$, and $155^{\circ} \mathrm{C}$ ) based on the final melting temperature from the DSC curve. This ensures that all the steps (peaks in the melting curve) would coincide in the different measurements and that the comparison of measurements would be easier. In all cases, the first $T_{\mathrm{s}}$ was in domain II as defined by Fillon et al., ${ }^{24}$ which is essential to the self-nucleation process. The melting temperature of the SSA measurement was taken from the largest peak in the melting curve.

\section{RESULTS AND DISCUSSION}

\section{Characterization of the Whole Samples}

Table II provides a summary of the molecular weight and molecular weight distribution (MWD) of all the samples. From samples A to D, the weight-average molecular weight increased gradually from 426000 to $498000 \mathrm{~g} / \mathrm{mol}$, while the MWD became broader. The table shows that sample $\mathrm{D}$ has a higher $M_{\mathrm{w}}$ of $498000 \mathrm{~g} / \mathrm{mol}$ and a broader MWD of 8.62 than any of the other samples.

Table III shows the isotacticity, ethylene content, and triad sequence distributions of the original samples. The ethylene contents of samples B, C, and D are 3.4, 12.1, and $30.3 \mathrm{~mol} \%$, respectively. With increased content, i.e., from samples $\mathrm{B}$ to $\mathrm{C}$, then $\mathrm{C}$ to $\mathrm{D}$, the isotacticity [mm] decreased from $91.9 \%$ to $86.7 \%, 79.7 \%$, and the triad PPP content decreased. Meanwhile, the EEE, PPE, EEP, EPE, and PEP contents increased

Table II. The molecular weight data of samples

\begin{tabular}{cccc}
\hline Sample & $M_{\mathrm{w}}\left(10^{-4}\right)$ & $M_{\mathrm{n}}\left(10^{-4}\right)$ & $M_{\mathrm{w}} / M_{\mathrm{n}}$ \\
\hline A & 42.6 & 9.83 & 4.33 \\
B & 46.7 & 7.53 & 6.20 \\
C & 46.9 & 6.88 & 6.82 \\
D & 49.8 & 5.78 & 8.62 \\
\hline
\end{tabular}

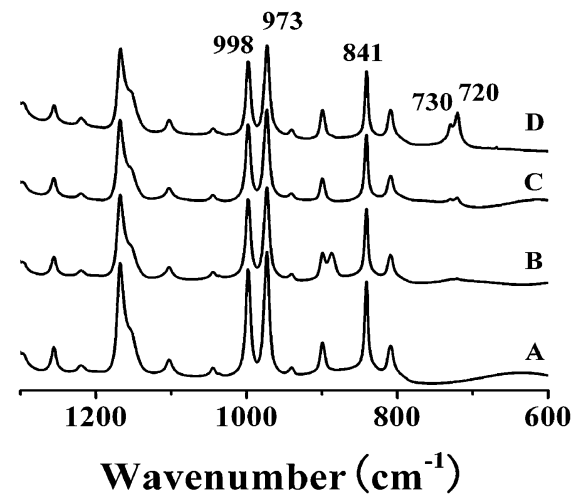

Figure 1. $\mathrm{IR}\left(1300-600 \mathrm{~cm}^{-1}\right)$ spectra of samples.

gradually; the number-average sequence length of the ethylene segments $\left(\mathrm{n}_{\mathbf{E}}: 3.4,3.7\right.$ and 4.0$)$ became very slightly longer, and the number-average sequence length of the propylene segments (nP: 96.6, 27.1 and 9.4) were significantly shorter. This shows that the ethylene units inserted into the PP chains shortened the PP sequence length and lowered the isotacticity. It can be seen that sample D, with the highest ethylene content, has a relatively homogeneous triad sequence distribution and the lowest isotacticity.

Figure 1 shows the FT-IR spectra for the original samples. Samples B, C, and D present a doublet at $720-730 \mathrm{~cm}^{-1}$, which means that these samples had crystalline PE segments. ${ }^{15}$ The bands at 998 and $841 \mathrm{~cm}^{-1}$, which represent crystalline PP segments, are presented for these four samples. Sample A is an iPP homopolymer, so there was no band at 720 and $730 \mathrm{~cm}^{-1}$, but the bands at 998 and $841 \mathrm{~cm}^{-1}$ were very strong. Obviously, the bands at 720 and $730 \mathrm{~cm}^{-1}$ were stronger with increasing ethylene content.

However, the analysis on average values of the microstructure for the original samples is not sufficient to explain the different microstructures and properties completely. Information concerning the microstructure distribution of $\mathrm{PP} / \mathrm{EPR}$ alloys is necessary in order to elucidate the effect of copolymerization time on microstructure and properties. This can be obtained via fractionation and subsequent characterization of fractions by GPC, FT-IR, NMR, and DSC characterization.

\section{Fractionation Results}

Samples B, C, and D were fractionated into five fractions, respectively, according to a procedure stated in the experimental part (fractions 1 to 5). Table IV lists the fractionation results and the molecular characterization data. It shows that these fractions were not separated according to molar mass.

Table III. The content of the ethylene monomer, triad sequence distributions and isotacticity of samples B, C and D

\begin{tabular}{ccccccrrrrr}
\hline Sample & E & PPP & PPE & EPE & PEP & EEP & EEE & $n_{P}$ & $n_{E}$ & mm \\
\hline B & 0.034 & 0.946 & 0.015 & 0.005 & 0.007 & 0.009 & 0.018 & 96.6 & 3.4 & 0.919 \\
C & 0.121 & 0.835 & 0.031 & 0.013 & 0.017 & 0.032 & 0.072 & 27.1 & 3.7 & 0.867 \\
D & 0.303 & 0.594 & 0.058 & 0.045 & 0.033 & 0.085 & 0.186 & 9.4 & 4.0 & 0.797 \\
\hline
\end{tabular}


Table IV. The fractionation results and molecular characterization data

\begin{tabular}{ccccccc}
\hline Sample & Fraction & wt \% & $M_{\mathrm{w}}\left(10^{-4}\right)$ & $M_{\mathrm{n}}\left(10^{-4}\right)$ & $M_{\mathrm{w}} / M_{\mathrm{n}}$ & $\mathrm{C}_{2}(\mathrm{~mol} \%)$ \\
\hline \multirow{4}{*}{ B } & B1 & 6.0 & 31.6 & 3.93 & 8.04 & 30.0 \\
& B2 & 3.9 & 23.3 & 2.69 & 8.68 & 23.2 \\
& B3 & 4.9 & 14.0 & 2.81 & 4.97 & 3.7 \\
& B4 & 14.5 & 16.4 & 5.98 & 2.73 & 0.4 \\
& B5 & 70.7 & 55.6 & 19.7 & 2.83 & 0 \\
\hline \multirow{4}{*}{ C } & C1 & 11.8 & 25.6 & 3.24 & 7.90 & 43.0 \\
& C2 & 5.2 & 28.5 & 4.27 & 6.67 & 45.0 \\
& C3 & 4.5 & 26.4 & 3.72 & 7.10 & 16.8 \\
& C4 & 18.7 & 23.5 & 8.16 & 2.88 & 1.7 \\
& C5 & 59.8 & 52.9 & 18.8 & 2.81 & 1.5 \\
\hline \multirow{4}{*}{ D } & D1 & 19.9 & 22.6 & 2.30 & 9.83 & 57.8 \\
& D2 & 10.8 & 35.6 & 2.73 & 13.0 & 67.0 \\
& D3 & 6.7 & 26.7 & 2.48 & 10.7 & 65.8 \\
& D4 & 44.3 & 53.6 & 15.3 & 3.50 & 2.1 \\
& D5 & 18.3 & 56.7 & 15.6 & 3.63 & 1.1 \\
\hline
\end{tabular}

Fraction 1: soluble at room temperature; fraction 2: soluble at $80^{\circ} \mathrm{C}$; fraction 3: soluble at $100^{\circ} \mathrm{C}$; fraction 4 : soluble at $115^{\circ} \mathrm{C}$; fraction 5 : insoluble at $115^{\circ} \mathrm{C}$.
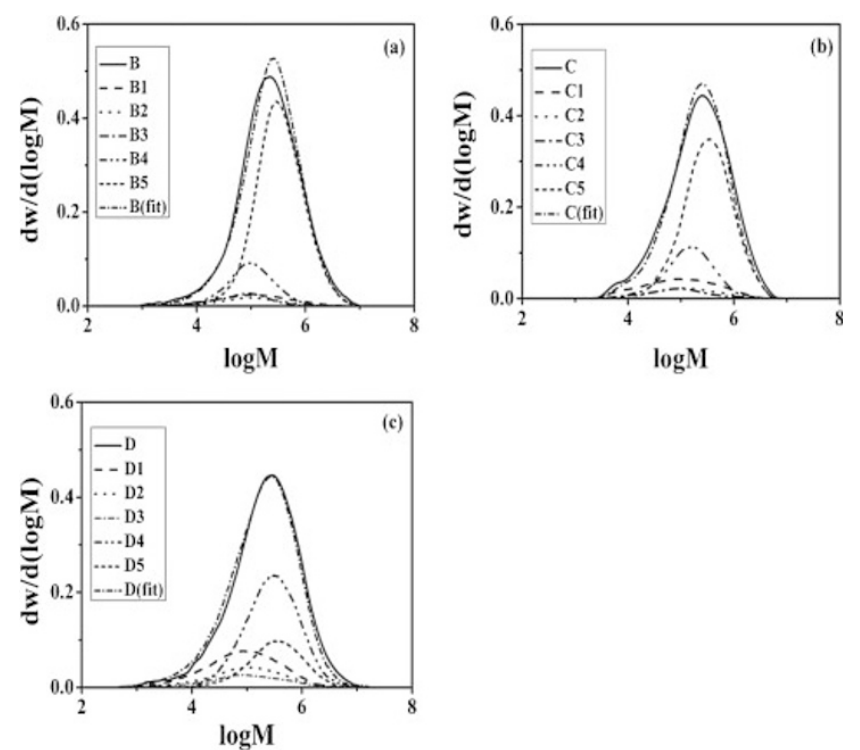

Figure 2. Molecular weight distribution profiles of sample $B(a), C(b)$ and $D$ (c) with the weighted distributions of the fractions and their sums.

For all samples, fraction 5 has the highest $M_{\mathrm{w}}$. The fraction distribution is quite different for the three samples. With increasing copolymerization time, the contents of fractions 1 , 2, 3, and 4 increased, while that of fraction 5 decreased. Sample D exhibits a broader composition distribution. The major part of the alloys, i.e., fractions 4 and 5, is collected above $100{ }^{\circ} \mathrm{C}$. Sample B has the highest content of $85.2 \mathrm{wt} \%$ for above $100{ }^{\circ} \mathrm{C}$ fractions.

Figure 2 shows the original samples along with the weighted GPC curves of the fractions and their sums. The sum of the GPC curves of the fractions agrees well with the GPC curves of the unfractionated samples, hence suggesting that the fractionation method used in this work was efficient, and that no degradation happened.

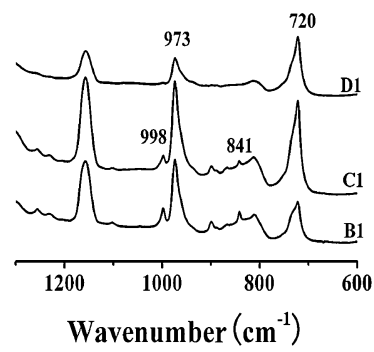

(a)

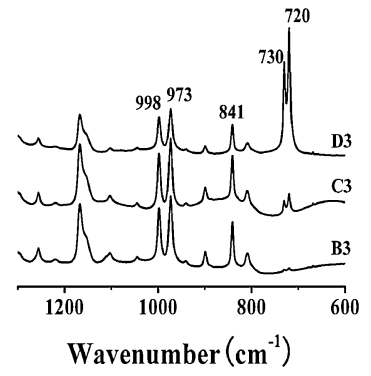

(c)

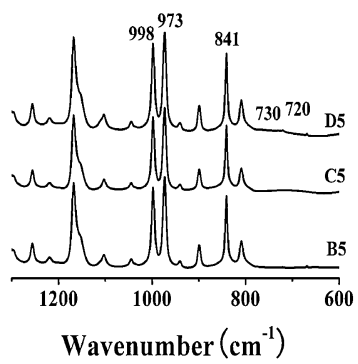

(e)

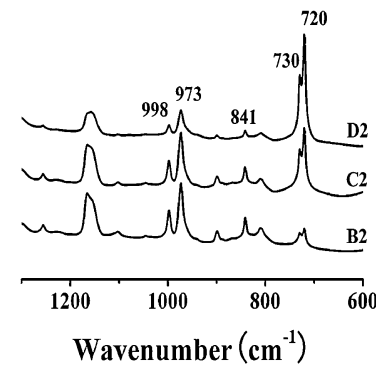

(b)

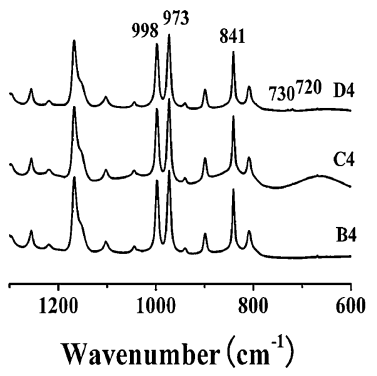

(d)
Figure 3. IR spectra $\left(1300-600 \mathrm{~cm}^{-1}\right)$ of fractions of samples $B, C$ and $D$ : (a) fraction 1; (b) fraction 2; (c) fraction 3; (d) fraction 4; (e) fraction 5 .

\section{FT-IR Analysis}

Figure 3 shows the FT-IR spectra of the fractions. A single band at $722 \mathrm{~cm}^{-1}$ occurred in the spectra of fraction 1 and was stronger than the original sample. The bands at 998 and $841 \mathrm{~cm}^{-1}$ were very weak, especially for D1. This shows that the ethylene content was higher than that of the original sample and that E segments were too short to crystallize. It also shows that the $\mathrm{P}$ segments were crystallizable, but the crystallinity was very low. Fraction 1 seemed to be an ethylene-propylene random copolymer.

For fractions 2 and 3, the doublet bands at $720-730 \mathrm{~cm}^{-1}$ were clearly seen, indicating crystallizable PE segments; nevertheless, these bands in B3 became very weak because of low ethylene content. Meanwhile, the PP crystalline bands were also visible. On the basis of the relative intensities of the characteristic IR bands of PE and PP, we considered that the fractions D2 and D3 contained more ethylene units than did the corresponding fractions in samples $\mathrm{B}$ and $\mathrm{C}$, and the ethylene content in fractions D2 and D3 were higher than the propylene content. 
Table V. The content of the ethylene monomer, triad sequence distributions and number-average sequence length of the comonomer blocks

\begin{tabular}{|c|c|c|c|c|c|c|c|c|c|c|c|}
\hline Sample & Fraction & $E$ & PPP & PPE & EPE & PEP & PEE & EEE & $n_{P}$ & $\mathrm{n}_{\mathrm{E}}$ & $\mathrm{mm}$ \\
\hline \multirow{5}{*}{ B } & B1 & 0.300 & 0.481 & 0.153 & 0.066 & 0.085 & 0.110 & 0.105 & 5.0 & 2.1 & 0.388 \\
\hline & B2 & 0.232 & 0.671 & 0.075 & 0.022 & 0.038 & 0.046 & 0.148 & 12.7 & 3.8 & 0.617 \\
\hline & B3 & 0.037 & 0.932 & 0.031 & 0 & 0.010 & 0.005 & 0.022 & 68.8 & 2.6 & 0.800 \\
\hline & B4 & 0.004 & 0.993 & 0.003 & 0 & 0.002 & 0 & 0.002 & 398.6 & 1.4 & 0.942 \\
\hline & B5 & 0 & 1 & 0 & 0 & 0 & 0 & 0 & - & - & 0.977 \\
\hline \multirow{5}{*}{$C$} & $\mathrm{C} 1$ & 0.430 & 0.311 & 0.170 & 0.089 & 0.094 & 0.171 & 0.165 & 3.2 & 2.4 & 0.339 \\
\hline & $\mathrm{C} 2$ & 0.450 & 0.432 & 0.080 & 0.038 & 0.040 & 0.088 & 0.322 & 6.5 & 5.4 & 0.531 \\
\hline & C3 & 0.168 & 0.807 & 0.020 & 0.005 & 0.007 & 0.010 & 0.151 & 72.4 & 14.6 & 0.810 \\
\hline & $\mathrm{C} 4$ & 0.017 & 0.983 & 0 & 0 & 0 & 0 & 0.017 & - & - & 0.960 \\
\hline & $\mathrm{C} 5$ & 0.015 & 0.985 & 0 & 0 & 0 & 0 & 0.015 & - & - & 0.976 \\
\hline \multirow{5}{*}{ D } & $\mathrm{D} 1$ & 0.578 & 0.150 & 0.156 & 0.116 & 0.103 & 0.233 & 0.242 & 3.4 & 2.6 & 0.251 \\
\hline & D2 & 0.670 & 0.166 & 0.085 & 0.076 & 0.046 & 0.143 & 0.484 & 2.8 & 5.7 & 0.425 \\
\hline & D3 & 0.658 & 0.292 & 0.026 & 0.027 & 0.012 & 0.059 & 0.584 & 8.9 & 15.9 & 0.704 \\
\hline & D4 & 0.021 & 0.973 & 0.005 & 0.001 & 0.001 & 0.002 & 0.018 & 279.7 & 10.5 & 0.968 \\
\hline & D5 & 0.011 & 0.985 & 0.003 & 0 & 0 & 0.002 & 0.010 & 494.5 & 11.0 & 0.969 \\
\hline
\end{tabular}

The spectra of both fractions 4 and 5 showed very strong crystallizable PP segments. The bands at 720 and $730 \mathrm{~cm}^{-1}$ became very weak. This indicates that the ethylene content and the content of the long ethylene segment were very low for fractions 4 and 5, and they were nearly pure PP homopolymers.

\section{NMR Analysis}

To study the chain structure of the different fractions further, ${ }^{13} \mathrm{C}$ NMR spectra were recorded; the calculated results are shown in Table $\mathrm{V}$, which also includes the $n_{\mathbf{E}}$ and $n_{\mathbf{P}}$.

The ethylene contents of B1, C1, and D1 were 30.0, 43.0, and $57.8 \mathrm{~mol} \%$, respectively. In fraction 1 , both ethylene and propylene sequence distributions in all triads were relatively homogeneous, while both $\mathrm{n}_{\mathbf{E}}$ and $\mathrm{n}_{\mathbf{P}}$ were very short. This confirms that fraction 1 was a random ethylene-propylene copolymer.

For fraction 2, both propylene and ethylene sequence distributions in all triads were evidently heterogeneous; the $\mathrm{PPP}+$ EEE contents in B2, C2, and D2 were 0.819, 0.754 and 0.650 , respectively, and both $n_{\mathbf{P}}$ and $n_{\mathbf{E}}$ became relatively longer than in fraction 1 , except for the $n_{\mathbf{P}}$ of D2. The FT-IR results of fraction 2 indicate that some of the ethylene and propylene segments were long enough to crystallize. These results prove that fraction 2 was an EP segmented copolymer.

For fraction 3, the ethylene contents of B3 (3.7 mol \%) and C3 $(16.8 \mathrm{~mol} \%)$ were much lower than those of B2 $(23.2 \mathrm{~mol} \%)$ and $\mathrm{C} 2(45.0 \mathrm{~mol} \%)$, respectively. D2 and D3 had approximate ethylene content, about $66 \mathrm{~mol} \%$. Both the $\mathrm{n}_{\mathbf{P}}$ and $\mathrm{n}_{\mathbf{E}}$ of fraction 3 were longer than that of fraction 2, except for the $\mathrm{n}_{\mathbf{E}}$ of $\mathrm{B} 3$ that had only $3.7 \mathrm{~mol} \%$ ethylene. The PPP + EEE contents in B3, C3, and D3 were 0.954, 0.958, and 0.876 , respectively, which are much higher than those of the other triads. We then combined the above results with further DSC data and obtained clear composition information.

In fractions 4 and 5 , the ethylene content was very low, and the isotacticity $[\mathrm{mm}]$ was higher than 0.942. Therefore, fractions 4 and 5 were composed of highly isotactic PP, which was interrupted by small amounts of long PE segments.

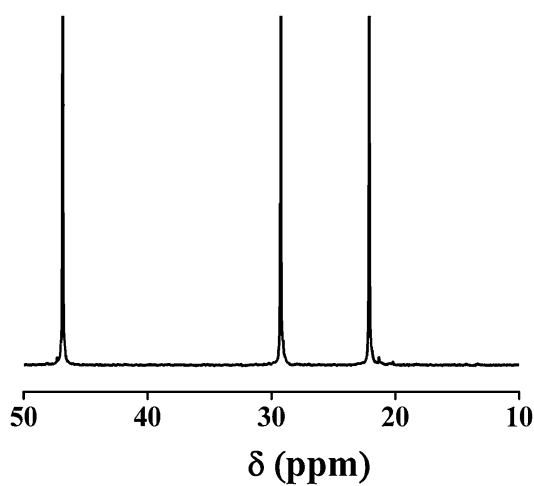

Figure 4. ${ }^{13} \mathrm{C}$ NMR spectra of the fraction $\mathrm{B} 5$

Definitely, B5 was a pure PP with very high isotacticity as shown in Figure 4. The molecular weight and isotacticity of fraction 5 were higher than those of fraction 4; this was due to the coincidence of molecular weight and isotacticity, as well as the intermolecular isotactic heterogeneity of different molecular weights PPs. This is consistent with the results found in the related literature. ${ }^{25-27}$

With increasing fractionation temperature, the ethylene content decreased, and $n_{\mathbf{P}}$ increased for the fractions from samples B and C. However, for sample D, the ethylene content in D1, D2, and D3 was 57.8, 67.0, and $65.8 \mathrm{~mol} \%$, higher than that of the propylene content of $42.2,33.0$, and $34.2 \mathrm{~mol} \%$. Moreover, D2 had the highest ethylene content $(67.0 \mathrm{~mol} \%)$ in all of the fractions. For the fractions collected at the same fractionation temperature, the fractions from sample $\mathrm{D}$, except D5, had the highest ethylene content compared with the others; in addition, the fractions from sample $B$ had the lowest ethylene content. In the fractions of B2, C2, and D2, $\mathrm{n}_{\mathbf{P}}$ decreased from 12.7 to $6.5,2.8$, while $n_{\mathbf{E}}$ increased from 3.8 to 5.4, 5.7. Fraction 3 had the same case. All these results show that a long copolymerization time leads to a longer crystallizable ethylene sequence length and a shorter crystallizable propylene sequence length. 

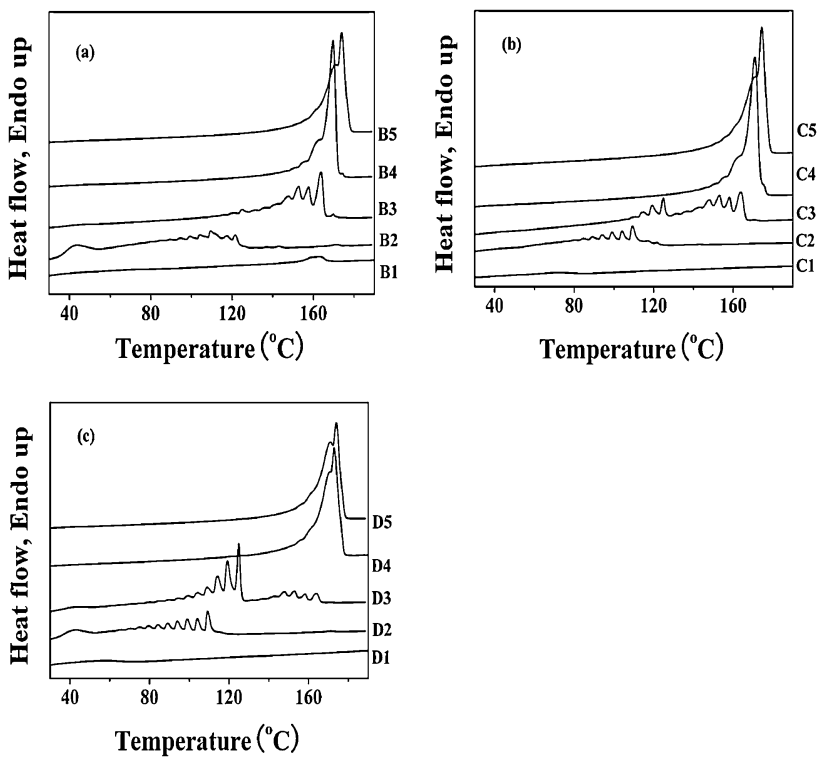

Figure 5. SSA melting curves of all fractions in samples B (a), C (b) and $\mathrm{D}(\mathrm{c})$.

\section{Thermal Analysis}

A thermal analysis of the fractions was also conducted to verify the microstructure of the different fractions. The results, through SSA measurement, are presented in Figure 5.

The typical DSC melting curves from fraction 1 without SSA treatment showed tiny peaks in the range of $30-90{ }^{\circ} \mathrm{C}$; this was due to the melting of PE crystals with considerable imperfection. Interestingly, B1 showed a weak peak at approximate $162^{\circ} \mathrm{C}$ close to the melting temperature of the PP homopolymer. This means that fraction 1 was mainly an amorphous EP random copolymer along with a few PP homopolymers soluble in xylene at room temperature because of the low molecular weight.

Fraction 2 showed multi-melting peaks below $130^{\circ} \mathrm{C}$ and some tiny peaks above $130^{\circ} \mathrm{C}$. The peaks above $130^{\circ} \mathrm{C}$ can be ascribed to PP sequences. However, those peaks lower than $130^{\circ} \mathrm{C}$ had a complicated composition. Combining the FT-IR and NMR data, the multi-melting peaks came from the segmented EP copolymers with PP and PE segments long enough to form crystalline lamellae. The lengths of the PP and PE segments were relatively short and had a rather broad distribution, so fraction 2 showed a low melting temperature and a broad melting range.

Fraction 3 had longer ethylene and propylene blocks than that in fraction 2, so the multi-melting peaks fell mainly between $100-180{ }^{\circ} \mathrm{C}$. B3, with only $3.7 \mathrm{~mol} \%$ ethylene, showed that the multi-melting peaks fell mainly between 130- $180^{\circ} \mathrm{C}$, corresponding to the melting of PP segments with different crystalline sequence lengths. As compared to the ethylene content of B3, those of C3 and D3 increased from 16.8 to $65.8 \mathrm{~mol} \%$, hence showing that more multi-melting peaks fell between $100-130^{\circ} \mathrm{C}$. Combining the FT-IR and NMR analysis, we concluded that most of the peaks below $130{ }^{\circ} \mathrm{C}$ were from the PE blocks with different crystalline sequence lengths; moreover, the multi-melting peaks above $130{ }^{\circ} \mathrm{C}$ resulted from the PP blocks with different crystalline sequence lengths. Both C3 and D3 were EP block copolymers with a broad distribution.

It should be noted that B3 and D4 had approximate ethylene content, but $\mathrm{B} 3$ can be dissolved in xylene at $100^{\circ} \mathrm{C}$, which was lower than $115^{\circ} \mathrm{C}$ of D4. B3 had a high triad PPP reaching 0.932; this shows that it was composed of PP homopolymer. However, a broad thermogram with multiple melting peaks shows a rather broad sequence length distribution of PP. B3 had a slight vibration at $720-730 \mathrm{~cm}^{-1}$, indicating the presence of crystalline ethylene segments $(n>4)$. Thus, B3 was composed of a PP homopolymer with a very low content of crystalline ethylene segments.

Fractions 4 and 5 had two main melting peaks in the region of $150-180^{\circ} \mathrm{C}$ from the longer crystalline propylene sequences. Meanwhile, the triad PPP from NMR data was above 0.973, and the isotacticity [mm] was above 0.942 for fractions 4 and 5, implying there were only a few compositional defects and steric defects in the polymer chains. Definitely, these two melting peaks were segregated not only by the molecular chain defects but also by some contribution from the meltingrecrystallization-remelting process during heating. ${ }^{18}$

By combining the results of FT-IR, NMR, and DSC analysis, we obtained a clear map for the chain structure and structure distribution of these PP/EPR in-reactor alloys. In these alloys, the ethylene-propylene random copolymer was available at room temperature fraction (fraction 1), and the PP homopolymer with a very low content of ethylene was included in over $100{ }^{\circ} \mathrm{C}$ fraction (fractions 4 and 5), these three fractions totally occupied more than $80 \mathrm{wt} \%$ of the alloy. The fractions at $80^{\circ} \mathrm{C}$ (fraction 2) and $100^{\circ} \mathrm{C}$ (fraction 3) were an ethylenepropylene segmented and block copolymer, respectively, except for B3. B3 was composed of a PP homopolymer with a very low content of crystalline ethylene sequences. In this paper, the fractionation technique TRDF was very similar to $\mathrm{TREF}^{28}$ in terms of fractionation mechanism. The extraction temperature was mainly determined by the chemical composition and crystallizability of the fraction.

The fractionation results and the characterization of the fractions also indicate that the ethylene content in the alloys, in the EPR, the EP segmented and the block copolymer increased with the copolymerization time. The weight percent of EPR, the EP segmented and block copolymer also increased with the copolymerization time. Sample D with $30.3 \mathrm{~mol} \%$ ethylene had more than $50 \%$ ethylene units in its EPR fraction and EP segmented copolymer fraction, respectively.

The three-dimensional wire surface plots of the TRDF-GPC cross fractionation of samples B, C, and D are shown in Figure 6. Each region on the surface gives the relative amount of species with a given molecular weight and composition. Although only five fractions were collected here, it still clearly shows the great heterogeneity and difference in the microstructure distribution of the three alloys in both composition and molecular weight. It is also shown that the weight percent 

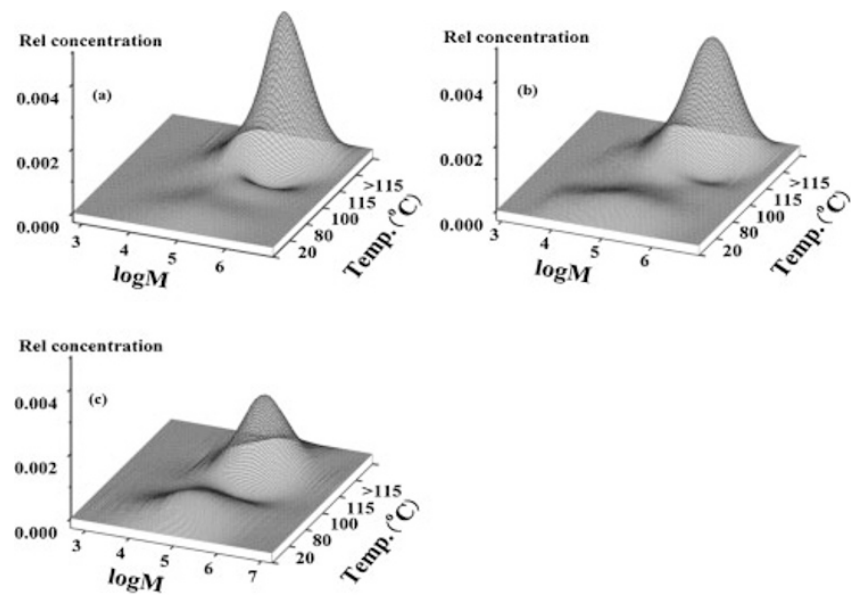

Figure 6. The 3D Wire Surface plots of the fractionation-GPC analysis of samples $B(a), C(b)$ and D (c).

of fractions below $100{ }^{\circ} \mathrm{C}$ (EPR, EP segmented and block copolymer) increased, and the weight percent of above $100^{\circ} \mathrm{C}$ fraction (PP homopolymer) decreased with the copolymerization time.

\section{CONCLUSIONS}

Three PP/EPR in-reactor alloys produced by a two-stage slurry/gas polymerization procedure, had different ethylene content and mechanical properties through controlling the copolymerization time. The three PP/EPR in-reactor alloys included four portions: ethylene-propylene random copolymer, i.e., EPR, ethylene-propylene segmented and block copolymer, and propylene homopolymer.

With the increasing copolymerization time from 30 to 60 , then 60 to $90 \mathrm{~min}$, the ethylene content in the alloys, in the EPR, and EP segmented and block copolymer became higher, while the weight percent of EPR, EP segmented and block copolymer also increased.

Since sample B, with the shortest copolymerization time of $30 \mathrm{~min}$ and only $3.4 \mathrm{~mol} \%$ ethylene content, contained $6.0 \%$ EPR and $3.9 \%$ EP segmented copolymer, its toughness could not be enhanced significantly. For the copolymerization time of 60 min, Sample C with $12.1 \mathrm{~mol} \%$ ethylene units had $11.8 \%$ EPR, 5.2 wt \% EP segmented copolymer and 4.5 wt \% EP block copolymer. Definitely, Sample C had an improved impact strength almost 7.7 times higher than that of sample A. Sample D had the longest copolymerization time of $90 \mathrm{~min}$ and $30.3 \mathrm{~mol} \%$ ethylene units. The sample had $19.9 \%$ EPR, $10.8 \mathrm{wt} \%$ EP segmented copolymer, and $6.7 \mathrm{wt} \%$ EP block copolymers. The ethylene content in EPR, segmented and block copolymers was about $58 \%, 67 \%$, and $66 \%$, respectively. Sample D possesses an excellent balance of stiffness and toughness.

Finally, an increase in the ethylene content in EPR, EP segmented and block copolymer, and a suitable weight percent of EPR are believed to be the key factors in the excellent toughness-stiffness balance for in-reactor alloys.

Acknowledgment. This work was subsidized by the National Basic Research Program of China (2005CB623806), National Natural Science Foundation of China (Key Project: 20734006, Innovation Group: 50621302), Chinese Academy of Sciences (KJCX2-SW-H07) and Petrochemical Research Institute, PetroChina. Co. Ltd.

Received: June 22, 2009

Accepted: August 16, 2009

Published: October 9, 2009

\section{REFERENCES}

1. R. Greco, C. Mancarella, E. Martuscelli, G. Ragosta, and J. Yin, Polymer, 28, 1929 (1987).

2. L. DOrazio, C. Mancarella, E. Martuscelli, and F. Polato, Polymer, 32, 1186 (1991).

3. X. Zhang, F. Xie, Z. Pen, Y. Zhang, and W. Zhou, Eur. Polym. J., 38, 1 (2002).

4. K. Premphet and P. Horanont, Polymer, 41, 9283 (2000).

5. C. De Rosa, F. Auriemma, V. Vinti, A. Grassi, and M. Galimberti, Polymer, 39, 6219 (1998).

6. J. Xu and L. Feng, Polym. Int., 47, 433 (1998).

7. Z. Fu, Z. Fan, Y. Zhang, and J. Xu, Polym. Int., 53, 1169 (2004).

8. Z. Fu, L. Feng, Z. Fan, and Y. Zhang, J. Appl. Polym. Sci., 97, 640 (2005).

9. Q. Zheng, Y. Shangguan, S. Yan, Y. Song, M. Peng, and Q. Zhang, Polymer, 46, 3163 (2005).

10. Q. Dong, X. Wang, Z. Fu, J. Xu, and Z. Fan, Polymer, 48, 5905 (2007).

11. L. Wang and B. Huang, J. Polym. Sci., Part B: Polym. Phys., 28, 937 (1990).

12. P. Galli and J. Haylock, Makromol. Chem. Macromol. Symp., 63, 19 (1992).

13. H. Cai, X. Luo, D. Ma, J. Wang, and H. Tan, J. Appl. Polym. Sci., 71, 93 (1999).

14. J. Xu, L. Feng, S. Yang, Y. Wu, Y. Yang, and X. Kong. Polymer, 38, 4381 (1997).

15. Z. Fan, Y. Zhang, J. Xu, H. Wang, and L. Feng, Polymer, 42, 5559 (2001).

16. Y. Zhang, Z. Fan, and L. Feng, J. Appl. Polym. Sci., 84, 445 (2002).

17. H. Tan, L. Li, Z. Chen, Y. Song, and Q. Zheng, Polymer, 46, 3522 (2005).

18. H. Zhu, B. Monrabal, C. C. Han, and D. Wang, Macromolecules, 41, 826 (2008).

19. L. Wild and T. Ryle, Polym. Prepr. (Am. Chem. Soc., Div. Polym. Chem.), 18, 182 (1977).

20. A. J. Müller, Z. H. Hernández, M. L. Arnal, and J. J. Sánchez, Polym. Bull., 39, 465 (1997).

21. A. J. Müller and M. L. Arnal, Prog. Polym. Sci., 30, 559 (2005).

22. F. Zhang, Y. Gong, and T. He, Eur. Polym. J., 39, 2315 (2003).

23. S. Wang and D. Yang, J. Polym. Sci., Part B: Polym. Phys., 42, 4320 (2004).

24. B. Fillon, J. C. Wittmann, B. Lotz, and A. Thierry, J. Polym. Sci., Part B: Polym. Phys., 31, 1383 (1993).

25. M. Kioka, H. Makio, A. Mizuno, and N. Kashiwa, Polymer, 35, 580 (1994).

26. J. Xu, L. Feng, S. Yang, Y. Yang, and X. Kong, Macromolecules, 30, 7655 (1997).

27. Y. Liu and S. Bo, Int. J. Polym. Anal. Charact., 8, 225 (2003).

28. Y. Feng and J. N. Hay, Polymer, 39, 6723 (1998). 